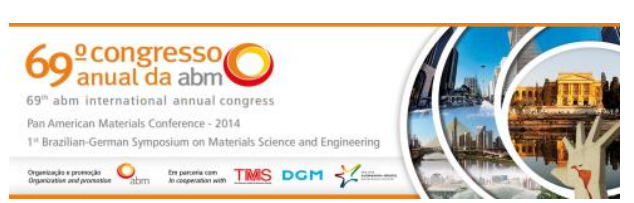

Tema: Engenharia de superfície

\title{
TRATAMENTOS DE SUPERFÍCIE DE FERRO REVESTIDO COM GRAFITA COM LASER A FIBRA*
}

\author{
Ivan Kwei Liu Kam ${ }^{1}$ \\ Milton Sergio Fernandes de Lima²
}

\begin{abstract}
Resumo
O presente trabalho propõe a carbonetação a laser de ferro puro para a formação de uma camada endurecida na superfície. A formação de uma camada dura permite obter peças com melhores propriedades tribológicas, mas sem alterar as propriedades volumétricas do sólido. Foram realizados experimentos em quatro condições de tratamento a laser, com uso de uma fonte do tipo fibra de Yb:vidro. Análises microestruturais e de dureza mostraram a formação de camada ledeburítica e martensítica, dependendo das condições experimentais, até cerca de $50 \mu \mathrm{m}$ de profundidade. Análises por calorimetria permitiram, também, verificar que a absortividade do laser na peça variou entre 30 e 46\%. Estes resultados mostram que o uso de laser para a carbonetação de peças ferrosas, com a metodologia proposta, permite um alto rendimento, alta dureza da superfície e baixo aporte térmico ao material.
\end{abstract}

Palavras-chave: Lasers; Endurecimento a laser; Carbonetação; Ferro.

\section{SURFACE TREATMENTS OF GRAPHITE COATED IRON WITH A FIBER LASER}

\section{Abstract}

This work proposes the laser carburizing of pure iron aiming the formation of a hard surface coating. This hard coating allows better tribological properties without changing the bulk properties of the solids. Four different laser treatments were carried out using a Yb:glass fiber laser. Microstructural and hardness analyses showed the appearance of ledeburite and martensite layers up to $50 \mu \mathrm{m}$ depth. Calorimetric analyses shown that the laser absorptivity at the surface were on the range 30 and $46 \%$. Accordingly to the current methodology, the laser carburizing of ferrous alloys could be accomplished with high efficiency, high surface hardness and low heat input in the material.

Keywords: Lasers; Laser hardening; Carburizing; Iron.

1 Graduando em Bacharelado em Ciência e Tecnologia, Universidade Federal de São Paulo, bolsista de Iniciação Científica, Instituto de Estudos Avançados, São José dos Campos, SP, Brasil.

2 Físico, mestre e doutor em engenharia metalúrgica, pesquisador/chefe da subdivisão de lasers, Divisão de Fotônica, Instituto de Estudos Avançados, São José dos Campos, SP, Brasil.

\footnotetext{
* Contribuição técnica ao $69^{\circ}$ Congresso Anual da ABM - Internacional e ao 14ํㅡㄹ ENEMET - Encontro Nacional de Estudantes de Engenharia Metalúrgica, de Materiais e de Minas, 21 a 25 de julho de 2014, São Paulo, SP, Brasil.
} 


\section{INTRODUÇÃO}

A engenharia de superfícies tem evoluído para propiciar o desenvolvimento de novos materiais com propriedades melhoradas, por meio da alteração da sua camada mais externa. Esta camada está sujeita aos fenômenos mais severos de emprego em serviço e, comumente, é responsável por estabelecer o tempo de vida de uma determinada peça. Em particular, os desenvolvimentos de engenharia de superfícies têm sido impulsionados pela possibilidade de usar fontes de laser para o aquecimento controlado de regiões selecionadas dos materiais.

No caso das ligas ferrosas, o emprego do laser tem sido focado em aumentar a dureza, a resistência ao desgaste e diminuir o coeficiente de atrito de peças de uso mecânico. Por exemplo, Lo et al. [1] utilizaram um laser do tipo Nd:YAG para tratar um aço AISI 440C produzindo uma camada de cerca de $100 \mu \mathrm{m}$ de profundidade, composta por martensita, carbonetos e austenita retida. A camada endurecida possuía uma dureza máxima de $800 \mathrm{HV}$, comparada com cerca de $300 \mathrm{HV}$ do material de base.

Fernandez-Vicente et al. [2] estudaram a possibilidade de tratar ferros fundidos com laser de forma a produzir uma camada endurecida por fusão em cilindros laminadores. A maioria das peças produzidas apresentou trincas devido à baixa tenacidade do ferro fundido resolidificado. Estes autores chegaram à conclusão que, no caso dos ferros fundidos perlíticos e bainíticos, deve-se proceder ao aquecimento sem fusão (endurecimento no estado sólido) a fim de evitar o trincamento, porém, nestas condições, obtém-se uma profundidade de endurecimento muito pequena. Esta fina camada advém da baixa absortividade da superfície do ferro, a qual pode ser aumentada com uso de uma camada absorvedora de grafita.

A possibilidade de utilizar uma camada absorvente de grafita sobre as ligas ferrosas já é conhecida há algum tempo. No início, era uma maneira de melhorar a absortividade (fração da intensidade incidente que é efetivamente absorvida pela peça na forma de calor) das superfícies, pois o carbono absorve muito mais o feixe de laser do que uma superfície metálica [3]. Na sequencia, alguns autores como Vasconcelos et al. [4] mostraram que o carbono, presente na superfície, poderia difundir melhorando as propriedades tribológicas das peças.

Yilbas et al. [5] estenderam o conceito de carbonetação dos aços inoxidáveis, classe SAE 304, pela aplicação de uma resina fenólica contendo $5 \%$ de partículas de TiC. $O$ efeito da carbonetação, junto com a adição de partículas duras, produziu um aumento na dureza de $230 \mathrm{HV}$ para $820 \mathrm{HV}$. O tratamento também resultou em uma camada com tensão residual compressiva da ordem de $-400 \mathrm{MPa}$, o que confere uma tenacidade a fratura superior na superfície tratada.

A maior parte da literatura relacionada com o problema de tratamentos de superfície com laser apresenta dois problemas. Primeiramente, não se sabe a quantidade de calor disponível para o aquecimento da peça. O desconhecimento da absortividade do laser na peça leva a parâmetros de processo que não se adequam ao tipo de material e não permitem prever as temperaturas nas quais as transformações de fase ocorrem. Segundo, como os autores já partem de ligas como ferros fundidos e aços, a análise fica complicada do ponto de vista metalúrgico. Isto porque um material ligado faz com que a diluição e a difusão do carbono sejam mais difíceis, portanto não representa um problema facilmente compreensível.

O presente estudo visa o entendimento da transferência de calor e massa durante a irradiação de peças de ferro puro, previamente revestidas de grafita, com vistas ao emprego da tecnologia para peças com superfície endurecida.

\footnotetext{
* Contribuição técnica ao $69^{\circ}$ Congresso Anual da ABM - Internacional e ao 14ํㅡㄹ ENEMET - Encontro Nacional de Estudantes de Engenharia Metalúrgica, de Materiais e de Minas, 21 a 25 de julho de 2014, São Paulo, SP, Brasil.
} 


\section{MATERIAIS E MÉTODOS}

Os materiais de partida foram obtidos de barras cilíndricas de ferro puro $(99,995 \% \mathrm{Fe})$ com 12,3 mm de diâmetro. O cilindro foi cortado em discos com $3 \mathrm{~mm}$ de espessura em máquina de eletroerosão a fio. Os discos foram então lixados com papel SiC600 para obter superfícies lisas e reprodutíveis. O peso de cada disco foi $2,85 \mathrm{~g}$.

O laser utilizado foi do tipo fibra de itérbio:vidro da marca IPG Photonics, modelo YLR-2000. O laser trabalha em modo contínuo, com potências de até $2000 \mathrm{~W}$. Uma mesa CNC realiza a movimentação da amostra com resolução de $0,01 \mathrm{~mm}$. O eixo $Z$, também controlado pela CNC, permite regular a focalização do laser sobre a superfície da amostra. O diâmetro mínimo do feixe é de $0,1 \mathrm{~mm}$. No presente estudo, não se utilizou atmosfera protetora.

Antes dos tratamentos, os discos foram aspergidos com spray de grafita coloidal da marca DNC. Não foi possível controlar a espessura da camada aplicada, mas o tempo de aplicação e a distância foram mantidos constantes nas amostras.

O porta-amostra foi especificamente desenhado para o presente trabalho, de forma a isolar termicamente a amostra. A Figura 1 apresenta o porta-amostra onde a peça fica suspensa por quatro parafusos, sendo que o parafuso de baixo não é visível na figura. O cabo preto contém o termopar que é fixado à superfície inferior da amostra de modo a monitorar a temperatura em função do tempo. A aquisição de dados foi feita por meio de termopares do tipo K (Cromel - Alumel) com transdutor da empresa Pico Technology Ltd., Modelo TC-08, que permite o monitoramento da temperatura por até 08 termopares. O software de controle é o PicoLog, instalado em um notebook padrão.

A amostra é empregada como um calorímetro, sendo a absortividade calculada através da Equação 1 [6].

$$
\beta=\frac{\mathrm{m} \cdot \mathrm{C}_{\mathrm{p}}\left(\mathrm{T}_{\max }-\mathrm{T}_{\mathrm{a}}\right)}{\mathrm{P} \cdot \Delta \mathrm{t}}
$$

Onde: $\beta$ é a absortividade média da amostra, $m$ é a massa do corpo de prova, Cp é o calor específico (em J/kgK), Tmax é a temperatura máxima atingida pela amostra, Ta é a temperatura ambiente, $\mathrm{P}$ é a potência do laser e $\Delta$ t é o tempo de interação do laser.

O tempo de interação é estimado pelo tempo no qual o feixe de laser atravessa a superfície plana da amostra, conforme mostrado na Figura 2. Este tempo é função da velocidade do feixe e do diâmetro da amostra, os quais são constantes aqui, e do espaçamento das linhas paralelas do tratamento, que é uma variável.

O procedimento experimental consistiu nas seguintes etapas:

a) Aspersão das amostras com o spray de grafita coloidal, seguido de secagem ao ar por quinze minutos;

b) Montagem no porta-amostras e posicionamento do termopar (Figura 1);

c) Programação da CNC: Foi realizado um padrão em forma de zig zag quadrado de $15 \times 15 \mathrm{~mm}$ de forma a passar sobre toda a amostra (Figura 2). O espaçamento entre as linhas foi variável e, portanto, o número de trilhas do laser sobre a superfície também foi variável. O número de passes é o número de vezes que o laser faz o trajeto representado na Figura 2.

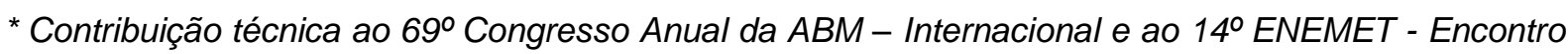
Nacional de Estudantes de Engenharia Metalúrgica, de Materiais e de Minas, 21 a 25 de julho de 2014, São Paulo, SP, Brasil.
} 
d) Ajuste da posição focal de forma a produzir um diâmetro de feixe na superfície da amostra: Conhecendo os parâmetros do feixe, diâmetro no plano focal, $\omega_{0}$, e qualidade do feixe, $M^{2}$, é possível calcular o diâmetro $\omega$ na posição relativa $Z$ conforme a Equação 2, para um feixe gaussiano.

$$
\omega(\mathrm{Z})=\omega_{0} \sqrt{1+\left(\frac{\lambda \mathrm{ZM}^{2}}{\pi \omega_{b}^{2}}\right)^{2}}
$$

Onde $\lambda$ é o comprimento de onda do laser $(1,07 \mu \mathrm{m})$. $\mathrm{O}$ valor de $\mathrm{M} 2$ obtido para este laser em trabalhos anteriores é 12 e o valor de $\omega_{0}$ é $0.1 \mathrm{~mm}$.

e) Realização dos tratamentos e registro das temperaturas de processo. $\mathrm{Na}$ sequencia, os peças eram retiradas para análise.

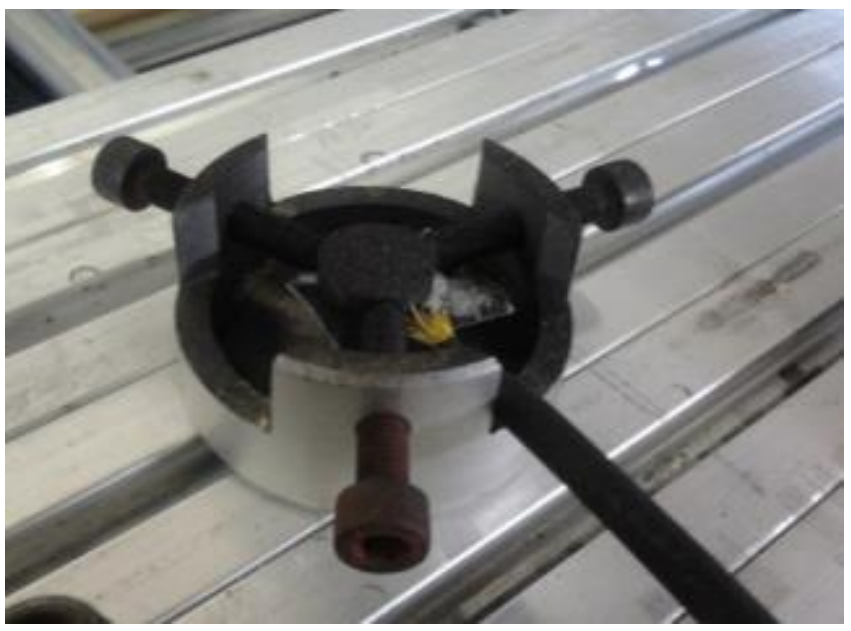

Figura 1. Porta-amostras para tratamento.

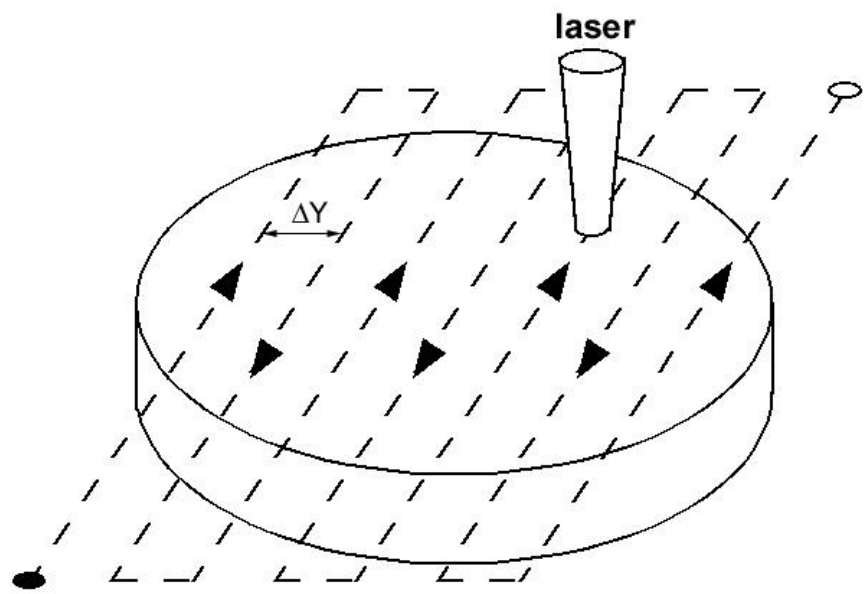

Figura 2. Representação esquemática do processo, com linhas pontilhadas representando a trajetória do feixe de laser.

Após o tratamento, as amostras foram cortadas com a máquina Precision Cutter modelo PC 10 da Imptech, usando um disco de diamante, e parte delas foi embutida no baquelite utilizando a máquina da Arotec PRE-30. Após o embutimento, foi realizado o processo de lixamento utilizando o equipamento da Arotec APL-4 juntamente com as lixas SiC 80, 100, 200, 400,600, 800 e 1200. Depois de lixadas,

* Contribuição técnica ao 69 Congresso Anual da ABM - Internacional e ao 14ํㅡㄹ ENEMET - Encontro Nacional de Estudantes de Engenharia Metalúrgica, de Materiais e de Minas, 21 a 25 de julho de 2014, São Paulo, SP, Brasil. 


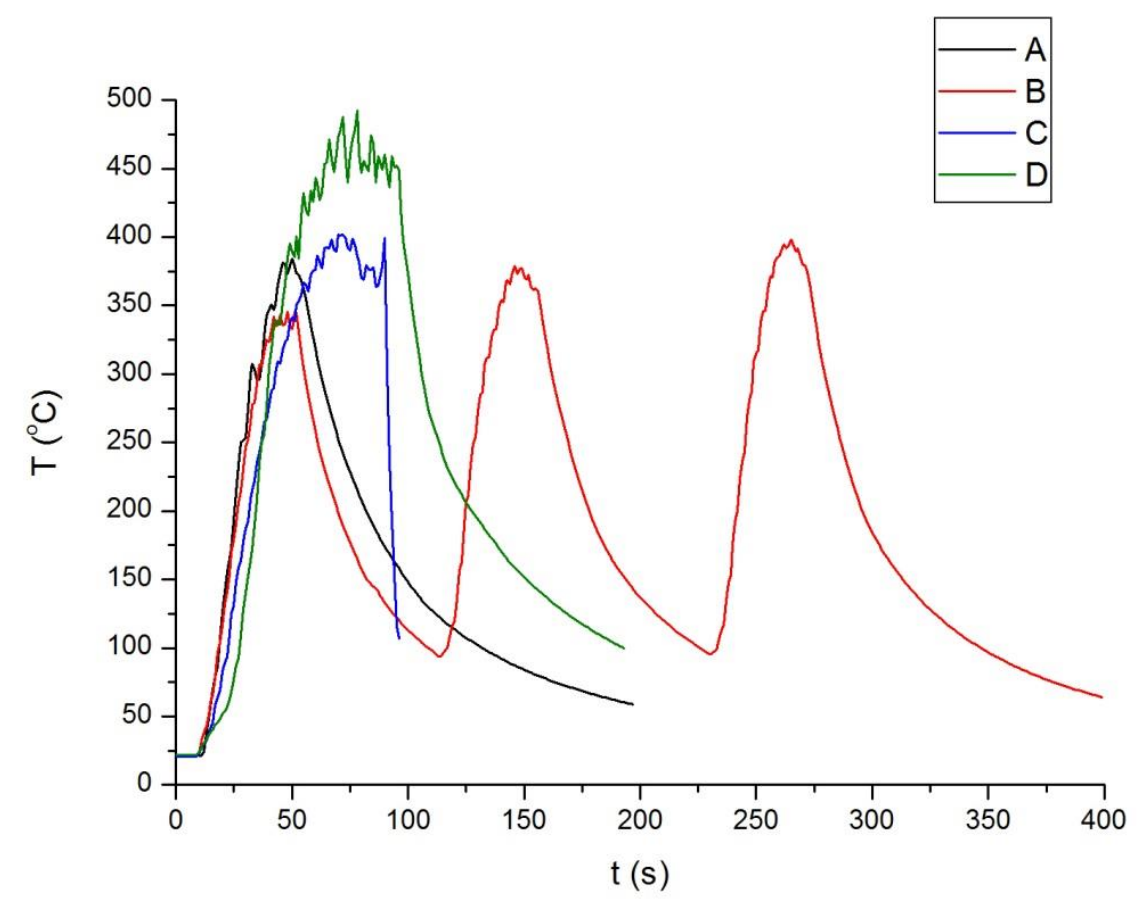

Figura 3. Medidas de temperatura em função do tempo para as quatro condições experimentais.

A temperatura máxima no volume ( $\left.T_{\text {vol }}\right)$, conforme observado na Tabela 2 , é de $400 \pm 50^{\circ} \mathrm{C}$. Para que se possam prever os efeitos desta temperatura na amostra, como um todo, se faz útil observar o diagrama de fases do sistema Fe-C conforme mostrado na Figura 4a [7]. O diagrama da Figura 4a mostra as fases presentes em equilíbrio termodinâmico, sendo $\delta, y$ e a as formas alotrópicas do ferro puro, $G$ a fase grafita e $L$ a fase líquida. $O$ volume da amostra é composto por ferro puro e não sofre mudança de fase, pois a transição $\alpha \rightarrow \gamma$ ocorre acima de $740^{\circ} \mathrm{C}$. Portanto, o tratamento laser não promove mudança significativa na estrutura e nas propriedades da peça, estando esta confinada a um volume próximo à superfície da amostra.

Tabela 1. Resultados das temperaturas máximas medida e estimada.

\begin{tabular}{|c|c|c|c|}
\hline Temperaturas & $\mathrm{T}_{\mathrm{vol}} /{ }^{\circ} \mathrm{C}$ & $\mathrm{T}_{\max } /{ }^{\circ} \mathrm{C}$ & $\beta$ \\
\hline Amostra A & 381 & 584,0 & $39,7 \%$ \\
\hline $\begin{array}{l}\text { Amostra B } \\
1^{\circ} \text { Passe }\end{array}$ & 345 & 666,0 & $44,3 \%$ \\
\hline $\begin{array}{l}\text { Amostra B } \\
2^{\circ} \text { Passe }\end{array}$ & 379 & 640,3 & $42,1 \%$ \\
\hline $\begin{array}{l}\text { Amostra B } \\
3^{\circ} \text { Passe }\end{array}$ & 398 & 676,8 & $46,0 \%$ \\
\hline Amostra C & 402 & * & * \\
\hline Amostra D & 493 & 923,9 & $30,3 \%$ \\
\hline
\end{tabular}

* O termopar desprendeu e não foi possível realizar a medida da temperatura em função do tempo para o resfriamento.

A Tabela 2 também apresenta as temperaturas máximas $\left(T_{\max }\right)$ obtidas pela extrapolação da curva de resfriamento, conforme o formalismo já descrito. Podem-se

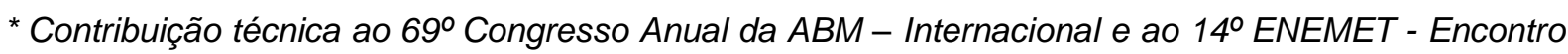
Nacional de Estudantes de Engenharia Metalúrgica, de Materiais e de Minas, 21 a 25 de julho de 2014, São Paulo, SP, Brasil. 
observar na superfície temperaturas maiores, entre 584,0 e $923,9^{\circ} \mathrm{C}$. Estas temperaturas permitem antever algumas transformações de fases importantes, com a transformação $\alpha \rightarrow \gamma$, para o ferro puro, a $740^{\circ} \mathrm{C}$ e a formação do eutéctico $\mathrm{Fe}-\mathrm{C}$ em cerca de $1150^{\circ} \mathrm{C}$.

Devido à aplicação de carbono sobre a superfície da peça, a absortividade do laser sobre a peça com carbono é maior do que a peça sem a aplicação de carbono. A absortividade medida nos experimentos varia de $30,3 \%$ a 46,0 \%. A absortividade do ferro sem revestimento de grafita se situa entre 8 e $10 \%$ [3].

No caso da amostra $B$, embora tenha sido realizado três passes em uma amostra isolada termicamente, não houve um aumento exagerado na temperatura. Aumentando $\mathrm{T}_{\text {vol }}$ de $345^{\circ} \mathrm{C}$ a $398^{\circ} \mathrm{C}$ do primeiro ao terceiro passe, ou seja, é possível tratar a peça com vários passes sem que ocorram transformações de fase na peça sendo tratada.
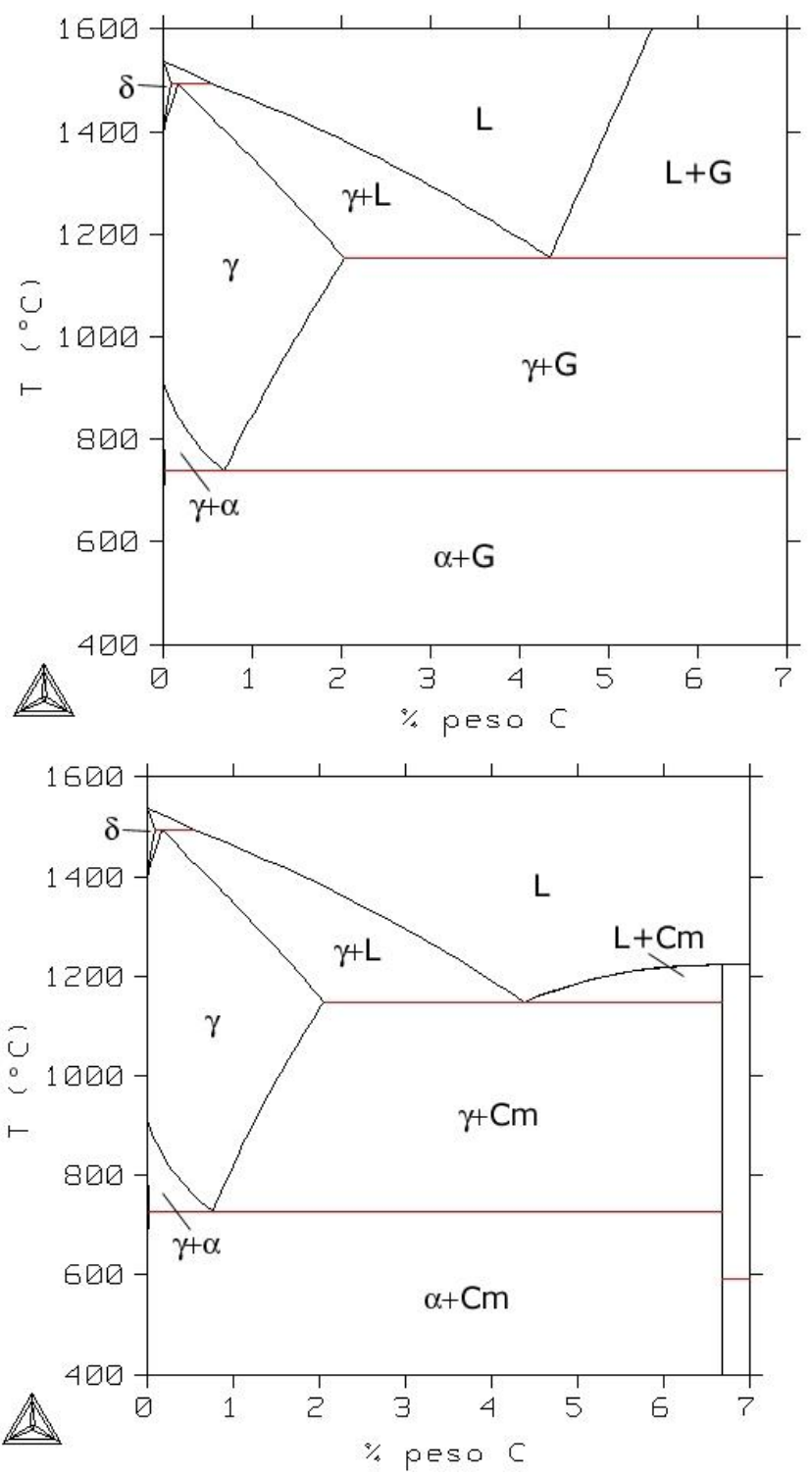

(a)

(b)

Figura 4. Diagrama de fases ferro-carbono: (a) equilíbrio estável e (b) equilíbrio metaestável.

A Figura 5 apresenta uma representação esquemática do processo, desde a fusão devido ao aquecimento pelo feixe de laser até a solidificação. Na Figura $5 a$, se vê

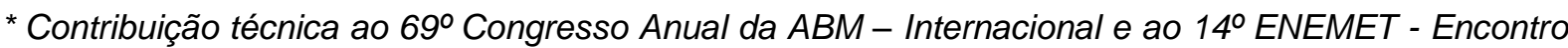
Nacional de Estudantes de Engenharia Metalúrgica, de Materiais e de Minas, 21 a 25 de julho de 2014, São Paulo, SP, Brasil.
} 


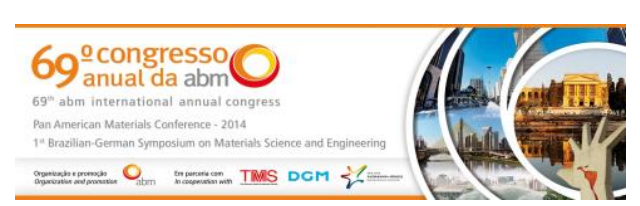

que o laser induz o surgimento do eutéctico $(E)$ na interface entre o Fe e a grafita (G). Enquanto houver calor, esta região de composição eutéctica cresce até atingir a superfície da peça (Figura $5 b$ ). A partir do momento que a poça de fusão atinge a superfície, o balanço entre carbono e ferro para se gerar o eutéctico se torna desfavorável e a composição se desloca para a esquerda no diagrama de fases da Figura 4a. A composição agora é hipoeutéctica (hE) e começam a aparecer núcleos da fase $y$-austenita dentro da poça.

Quando o laser deixa de atuar, inicia-se a solidificação. No entanto, isso se faz muito rapidamente e o diagrama de fases Fe-C (Figura $4 a$ ) não é mais válido. A solidificação ocorre segundo o diagrama de fases metaestável Fe-C (Figura 4b), onde o eutéctico é do tipo ferro mais cementita. Portanto, o que se espera é uma região ressolidificada composta por dendritas primárias de austenita numa matriz de ledeburita (Ld).

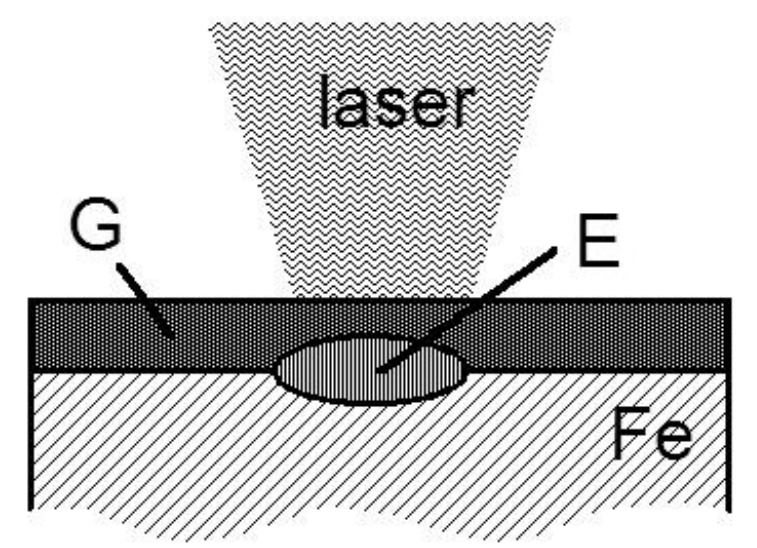

(a)

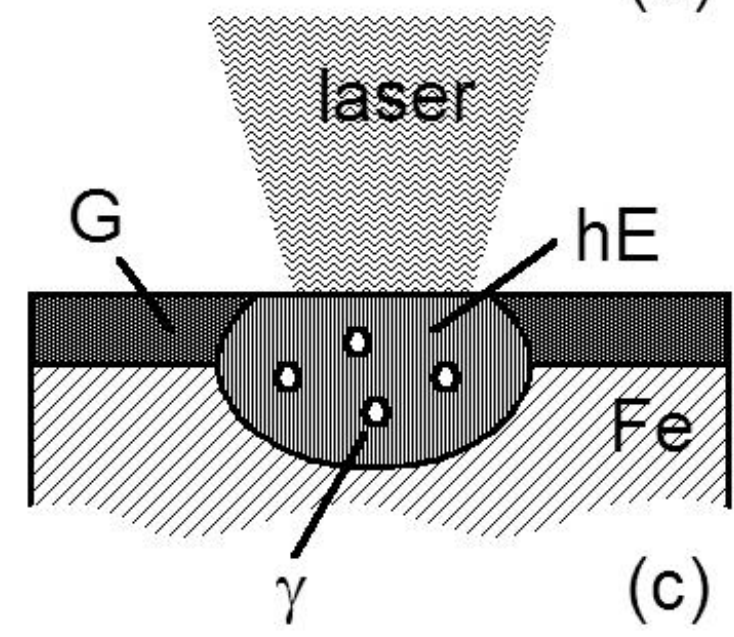

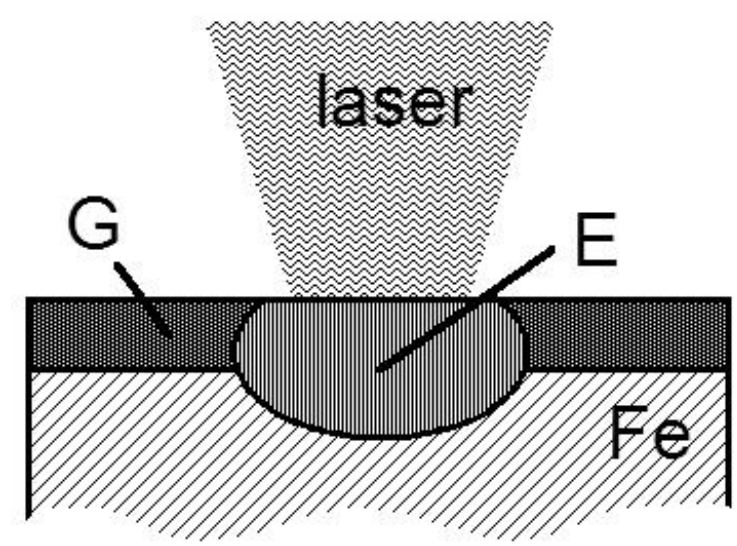

(b)

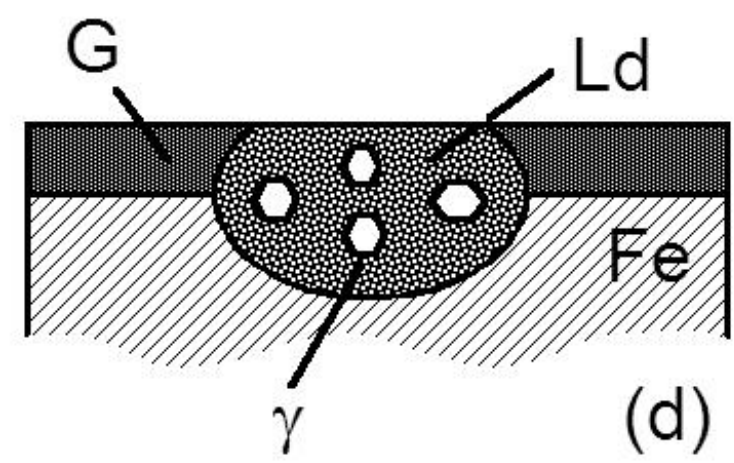

Figura 5. Representação esquemática do processo de fusão e solidificação no tratamento a laser.

Microestruturalmente se observa exatamente este tipo de microestrutura, conforme se vê na Figura 6. A condição A apresenta uma temperatura máxima na superfície (Tabela 2) muito pequena e não existe modificação microestrutural visível, portanto ela não é apresentada na Figura 6. Nas outras condições ( $B, C$ e $D)$ houve alterações microestruturais evidentes, com dendritas primárias da fase austenita, circundado por ledeburita, conforme previsto anteriormente. Nas regiões de sobreposição, como aquela apresentada na Figura 6C', são observadas agulhas de

\footnotetext{
* Contribuição técnica ao $69^{\circ}$ Congresso Anual da ABM - Internacional e ao 14ํㅡㄹ ENEMET - Encontro Nacional de Estudantes de Engenharia Metalúrgica, de Materiais e de Minas, 21 a 25 de julho de 2014, São Paulo, SP, Brasil.
} 


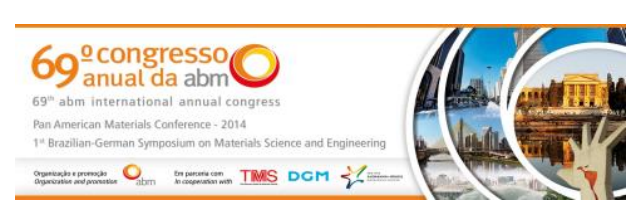

carbonetos. Estas agulhas se apresentam na amostra $\mathrm{C}$ porque neste caso a velocidade foi menor e o espaçamento entre as trilhas foi mais cerrado. Isso ocasiona um efeito de reaquecimento importante, com reações adicionais da ledeburita.

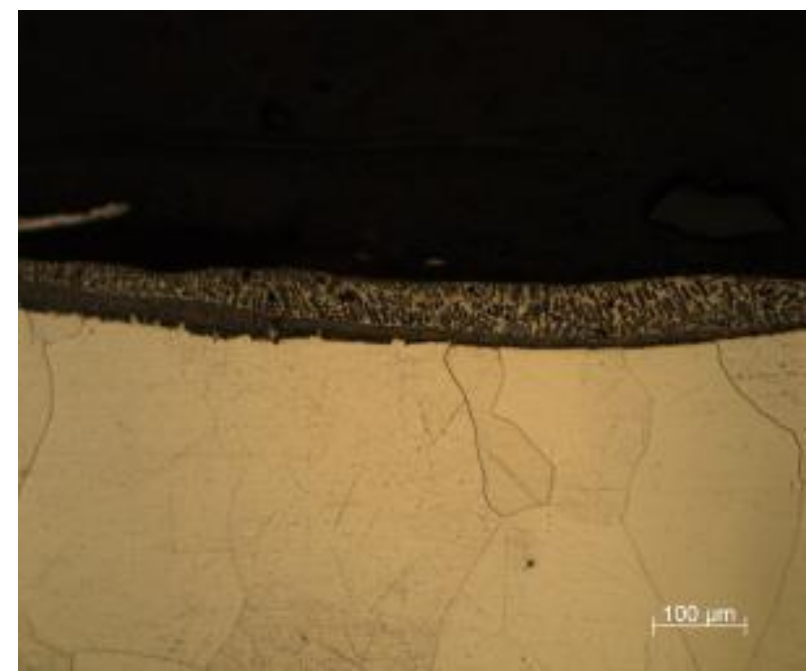

(B)

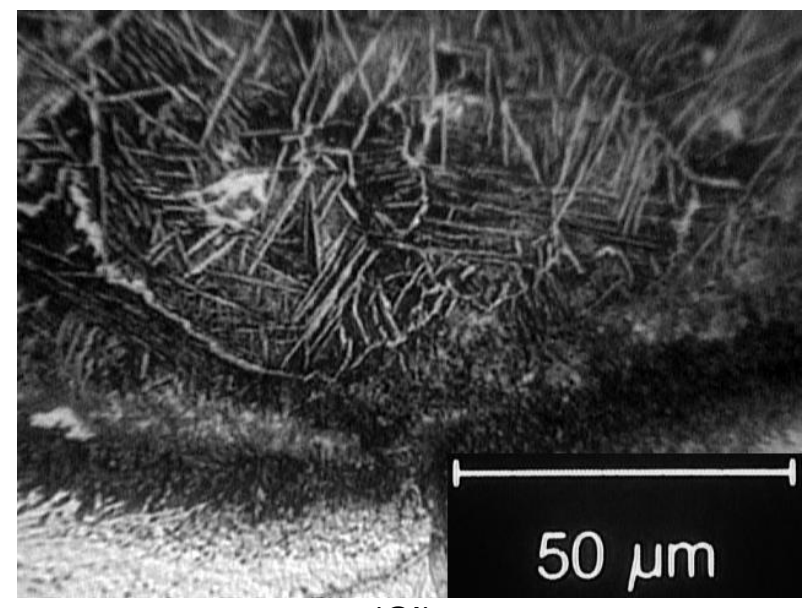

$\left(C^{\prime}\right)$

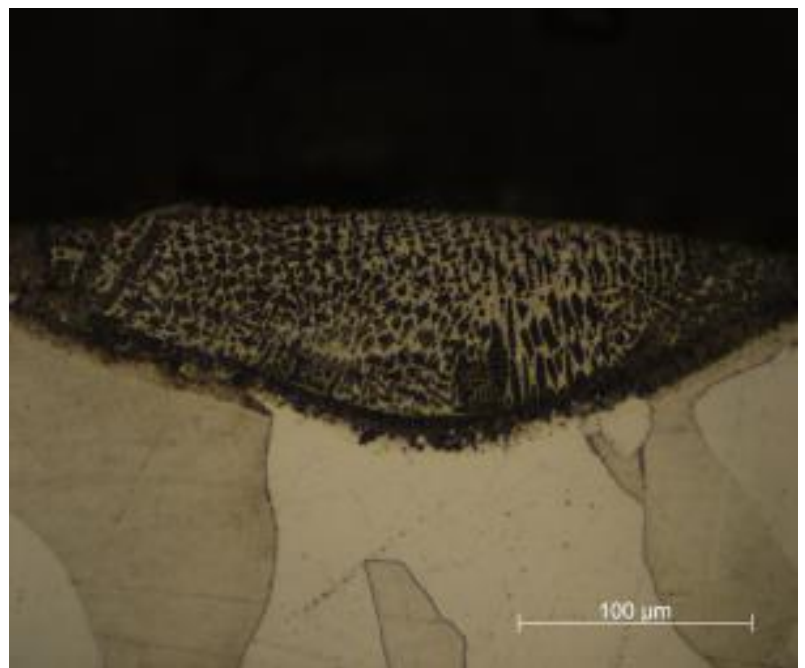

(C)

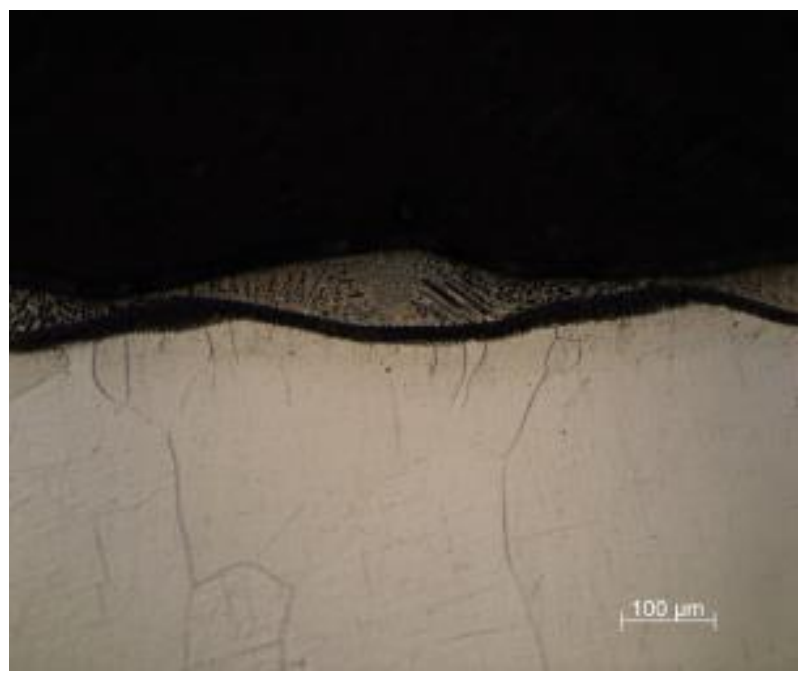

(D)

Figura 6. Micrografias obtidas das amostras em diferentes condições experimentais, sendo C' a mesma condição $\mathrm{C}$ obtida em região diferente.

A evolução microestrutural também pode ser verificada por meio de difratometria de raios- $X$, conforme mostrado na Figura 7 . Os difratogramas apresentam as fases grafita $(G)$, óxido de ferro (magnetita-O) e ferrita $(\alpha)$. A fase grafita está presente como um resquício da camada previamente depositada e tende a desaparecer com o aumento do número de passes, como é possível observar comparando-se a condição A com a B. O óxido ocorre naturalmente, pois o processo foi feito ao ar. A fase ferrita vem do material de base não transformado (cond. A) e da ledeburita. A austenita que se forma durante o processo se torna martensita no resfriamento, por isso a fase austenita não é visível nos difratogramas. Como os picos da martensita se sobrepõem à ferrita, não é possível discriminá-las nos difratogramas da Figura 7.

\footnotetext{
* Contribuição técnica ao 69 Congresso Anual da ABM - Internacional e ao 14ํㅡㄹ ENEMET - Encontro Nacional de Estudantes de Engenharia Metalúrgica, de Materiais e de Minas, 21 a 25 de julho de 2014, São Paulo, SP, Brasil.
} 


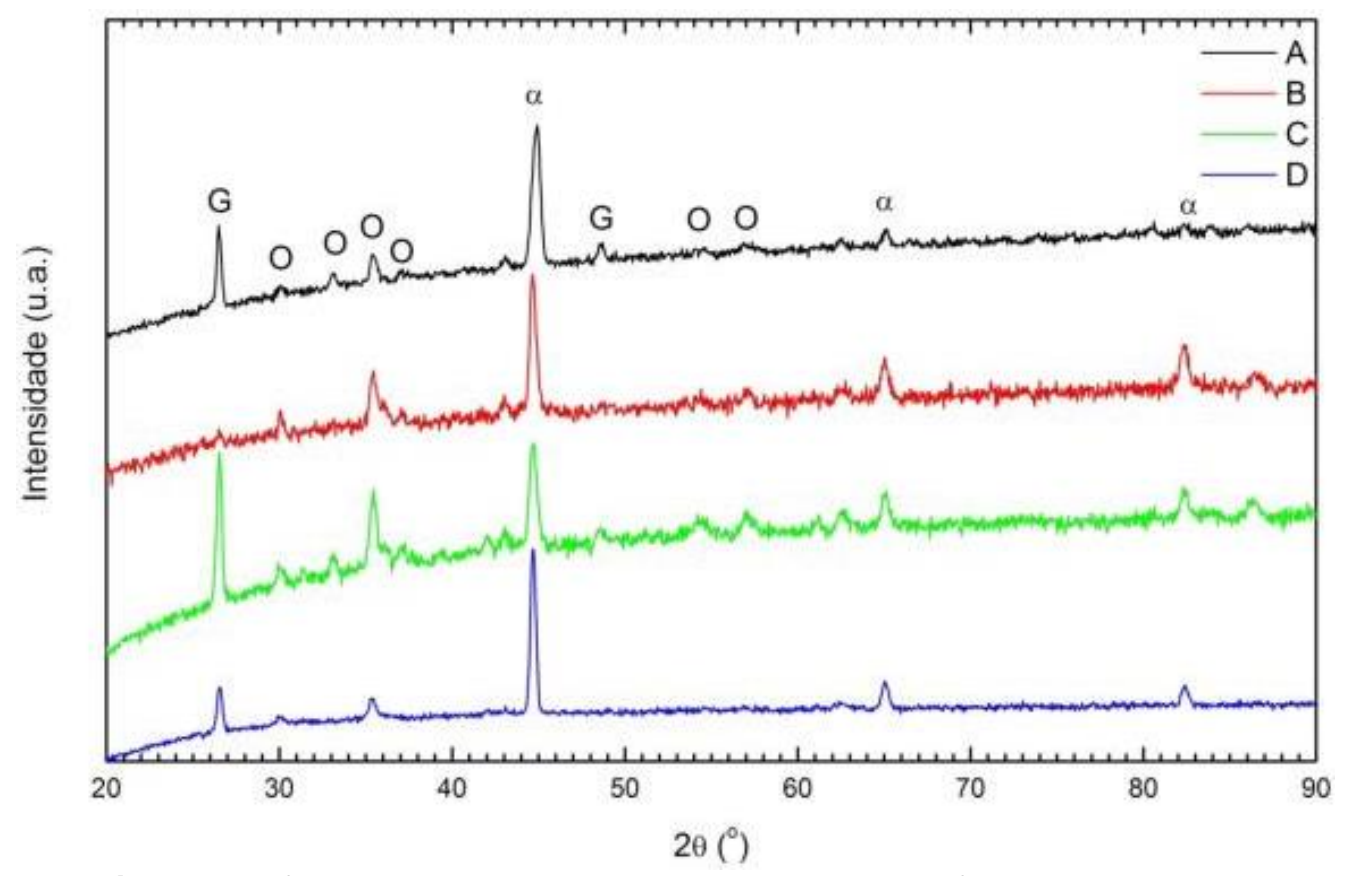

Figura 7. Difratogramas de raios- $X$ das amostras nas diferentes condições.

\subsection{Endurecimento da superfície tratada}

Na Figura 8 são apresentadas as curvas de dureza HV em função da profundidade (z) para as amostras $A$ a $D$. No caso da amostra $A$, não houve endurecimento visível. Ficando a dureza em torno de $90 \mathrm{HV}$, que é a dureza do metal base. Nos outros casos, B, C e D, a profundidade da região endurecida ficou em torno de 50 $\mu \mathrm{m}$. A variação na dureza próxima à superfície deve-se ao aparecimento de líquido, conforme mostrado na Figura 5, o que leva à formação de ledeburita. A ledeburita é menos dura que a martensita nesse sistema Fe-C. Portanto, a queda observada na região endurecida se deve à transição entre ledeburita e martensita próximas à superfície. Como se verifica na Figura 8, quando mais passes acontecem (cond. B), mais ledeburita é formada e a transição se faz mais visível.

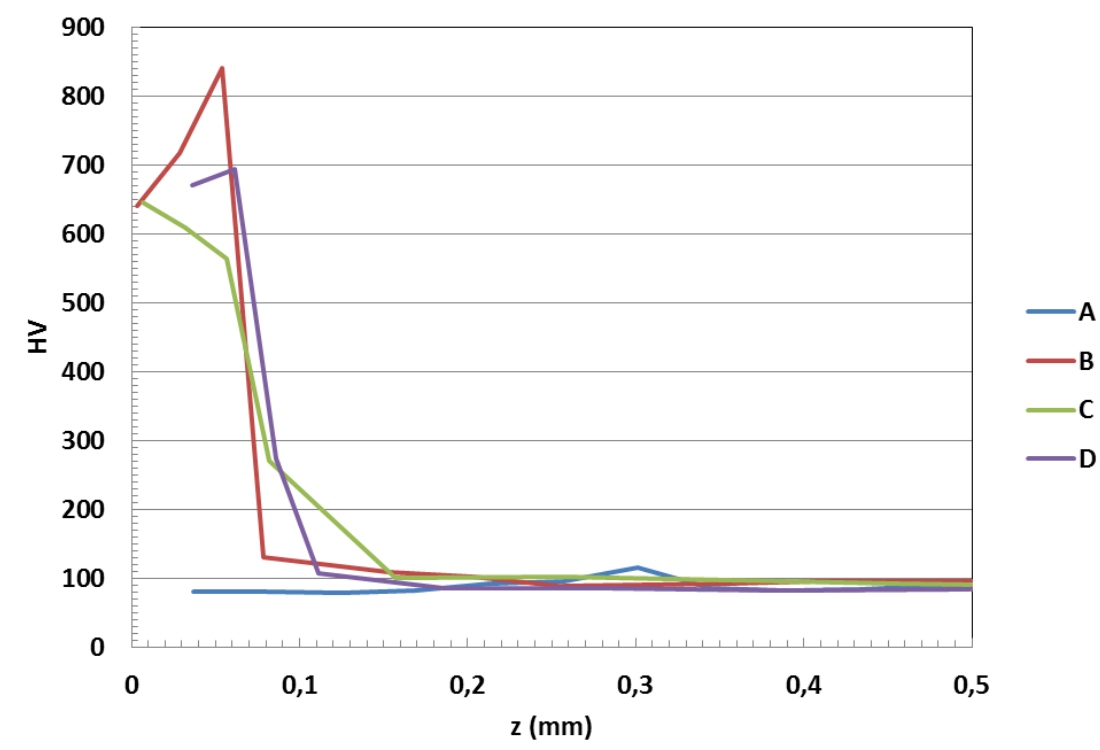

Figura 8. Gráfico de dureza (HV) em função da profundidade para as amostras em estudo.

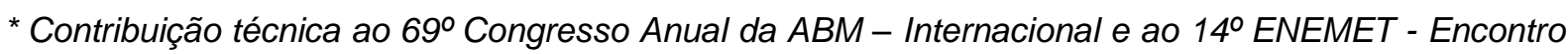
Nacional de Estudantes de Engenharia Metalúrgica, de Materiais e de Minas, 21 a 25 de julho de 2014, São Paulo, SP, Brasil.
} 


\section{CONCLUSÃO}

O presente estudo permite concluir o que segue:

a) $O$ presente método de endurecimento do ferro puro recoberto com grafita se mostrou eficiente para a formação de fases duras na superfície do material.

b) A temperatura atingida pelas amostras não ultrapassou temperaturas nas quais ocorre reação, portanto o volume das peças não sofreu modificações.

c) Por outro lado, a temperatura da superfície foi suficientemente alta para promover a carbonetação e fusão localizada, gerando ledeburita e martensita no resfriamento.

d) Foi possível determinar a absortividade nas amostras processadas, ficando entre 30 e $46 \%$, nos casos onde foi feito o estudo calorimétrico.

\section{Agradecimentos}

Os autores agradecem ao CNPq-Conselho Nacional de Pesquisas pela bolsa de iniciação científica do aluno Ivan K.L.Kam.

\section{REFERÊNCIAS}

1 Lo KH, Cheng FT, Man HC. Laser transformation hardening of AISI 440C martensitic stainless steel for higher cavitation erosion resistance. Surface and Coatings Technology. 2003;173: 96-104.

2 Fernández-Vicente A, Pellizzari M, Arias JL. Feasibility of laser surface treatment of pearlitic and bainitic ductile irons for hot rolls. Journal of Materials Processing Technology. 2012; 212:989-1002.

3 Ready JF. LIA Handbook of Laser Materials Processing. Orlando: Laser Institute of America \& Magnolia, Publishing, Inc.; 2001.

4 Vasconcelos G, Costa PNG, Antunes EF. Covering steel surfaces with carbon black by CO2 laser beam. Materials Science Forum. 2010; 660-666:249-252.

5 Yilbas BS, Akhtar SS, Matthews A, Karatas C. Laser treatment of carbon film coated steel surface, Surface Engineering. 2012;28(1):57-67.

6 Lima MSF, Wagniere JD. Determinação da absorção do feixe laser em ensaios de refusão em regime contínuo. Revista de Metalurgia. 1998; 32: 131 - 134.

7 ThermoCalc thermodynamic database, version J, Stockholm Royal Institute, Suécia, 1994.

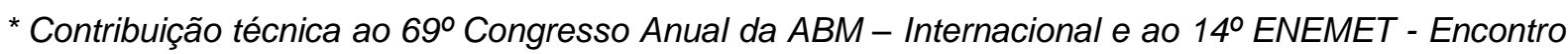
Nacional de Estudantes de Engenharia Metalúrgica, de Materiais e de Minas, 21 a 25 de julho de 2014, São Paulo, SP, Brasil.
} 